\title{
Cerebral Microvascular Obstruction by Fibrin is Associated with Upregulation of PAI-1 Acutely after Onset of Focal Embolic Ischemia in Rats
}

\author{
Zheng Gang Zhang, ${ }^{1}$ Michael Chopp, ${ }^{1,5}$ Anton Goussev, ${ }^{1}$ Dunyue Lu, ${ }^{2}$ Daniel Morris, ${ }^{3}$ Wayne Tsang, ${ }^{1}$ \\ Cecylia Powers, ${ }^{1}$ and Khang-Loon $\mathrm{Ho}^{4}$ \\ Departments of ${ }^{1}$ Neurology, ${ }^{2}$ Neurosurgery, ${ }^{3}$ Emergency Medicine, and ${ }^{4}$ Pathology, Henry Ford Health Sciences Center, \\ Detroit, Michigan 48202, and 5Department of Physics, Oakland University, Rochester, Michigan 48309
}

The mechanisms underlying cerebral microvascular perfusion deficit resulting from occlusion of the middle cerebral artery (MCA) require elucidation. We, therefore, tested the hypothesis that intravascular fibrin deposition in situ directly obstructs cerebral microcirculation and that local changes in type 1 plasminogen activator inhibitor (PAl-1) gene expression contribute to intravascular fibrin deposition after embolic MCA occlusion. Using laser-scanning confocal microscopy (LSCM) in combination with immunofluorescent staining, we simultaneously measured in three dimensions the distribution of microvascular plasma perfusion deficit and fibrin(ogen) immunoreactivity in a rat model of focal cerebral embolic ischemia $(n=12)$. In addition, using in situ hybridization and immunostaining, we analyzed expression of PAl-1 in ischemic brain $(n=13)$. A significant $(p<0.05)$ reduction of cerebral microvascular plasma perfusion accompanied a significant $(p<0.05)$ increase of intravascular and extravascular fibrin deposition in the ischemic lesion. Microvascular plasma perfusion deficit and

Occlusion of the middle cerebral artery (MCA) results in progressive impairment of downstream cerebral microvascular plasma perfusion (Crowell and Olsson, 1972; Little et al., 1975; Buchweitz-Milton and Weiss, 1988; Ennis et al., 1990). Using intravascular fluorescent tracer molecules or fluorescent tracers in combination with laser-scanning confocal microscopy (LSCM), we and others have shown a significant reduction of cerebral microvascular plasma perfusion and concomitant cerebral injury in the ischemic core at 1 and $4 \mathrm{hr}$ after MCA occlusion (Dawson et al., 1997; Zhang et al., 1999a). Data are emerging to suggest that intravascular fibrin deposition contributes to microvascular obstruction (Okada et al., 1994; Siebler et al., 1994; Heyes and Cervos-Navarro, 1996). For example, microvascular fibrin deposition accumulates during early focal cerebral ischemia, and reperfusion in the nonhuman primate and fibrin-containing microthromboemboli are found in acute human ischemic brain (Siebler et al., 1994; Heyes and Cervos-Navarro, 1996).

Received July 29, 1999; revised Sept. 10, 1999; accepted Sept. 29, 1999.

This work was supported by National Institute of Neurological Disorders and Stroke Grants PO1 NS23393 and RO1 NS33627. We gratefully acknowledge Drs. D. J. Loskutoff and D. Belin for providing us anti-PAI-1 antibody and PAI-1 cDNA. We thank Denice Bliesath for manuscript preparation and Cynthia Roberts and Xiuli Zhang for technical assistance.

Correspondence should be addressed to Dr. Michael Chopp, Henry Ford Hospital, Neurology Department, 2799 West Grand Boulevard, Detroit, MI 48202. E-mail: chopp@neuro.hfh.edu.

Copyright (C) 1999 Society for Neuroscience 0270-6474/99/1910898-10\$05.00/0 fibrin deposition expanded concomitantly from the subcortex to the cortex during 1 and $4 \mathrm{hr}$ of embolic MCA occlusion. Threedimensional analysis revealed that intravascular fibrin deposition directly blocks microvascular plasma perfusion. Vascular plugs contained erythrocytes, polymorphonuclear leukocytes, and platelets enmeshed in fibrin. In situ hybridization demonstrated induction of PAl-1 mRNA in vascular endothelial cells in the ischemic region at $1 \mathrm{hr}$ of ischemia. PAl-1 mRNA significantly increased at $4 \mathrm{hr}$ of ischemia. Immunohistochemical staining showed the same pattern of increased PAI-1 antigen in the endothelial cells. These data demonstrate, for the first time, that progressive intravascular fibrin deposition directly blocks cerebral microvascular plasma perfusion in the ischemic region during acute focal cerebral embolic ischemia, and upregulation of the PAl-1 gene in the ischemic lesion may foster fibrin deposition through suppression of fibrinolysis.

Key words: stroke; plasminogen activator inhibitor; rat; fibrin; microvascular; perfusion; confocal microscopy
A fibrin thrombus is formed from fibrinogen by activation of thrombin (Collen and Lijnen, 1991; Loscalzo and Schafer, 1992). Endogenous fibrinolysis is mediated by plasminogen activators that convert the zymogen plasminogen into the active serine protease plasmin. Plasmin is the primary enzyme responsible for removal of fibrin deposits (Collen and Lijnen, 1991; Vassalii et al., 1991; Plow et al., 1995). Type 1 plasminogen activator inhibitor (PAI-1) inhibits plasminogen activators in vivo (Loskutoff et al., 1989). PAI-1 is secreted by a variety of cells, including endothelial cells and platelets (Loskutoff et al., 1989; Braaten et al., 1993; Kollros et al., 1994; Stringer et al., 1994; Handt et al., 1996). Elevation of PAI-1 activity is associated with fibrin deposition after ischemia (Hamsten et al., 1987; Margaglione et al., 1994). Therefore, intravascular deposition of fibrin in ischemic brain suggests a perturbation of the procoagulant and fibrinolytic activation cascades.

Despite the increasing number of reports about the effects of fibrin deposition on microcirculatory impairment, information is lacking whether intravascular fibrin deposition in situ directly obstructs cerebral microcirculation and how local changes in PAI-1 gene expression contribute to intravascular fibrin deposition. In this report, we used three-dimensional LSCM in combination with immunofluorescent staining to investigate the effects of intravascular fibrin deposition on cerebral microvascular plasma perfusion deficits in a rat model of focal cerebral embolic ischemia (Zhang et al., 1997). In addition, using in situ hybrid- 
ization and immunostaining, we analyzed expression of PAI-1 in ischemic brain. Our data indicate that microvascular perfusion deficits after embolic stroke may be facilitated by increases in PAI-1 levels, leading to intravascular fibrin deposition.

\section{MATERIALS AND METHODS}

All experimental procedures have been approved by the Care of Experimental Animals Committee of Henry Ford Hospital.

Animal model. Male Wistar rats $(n=25)$ weighing $300-350$ gm were anesthetized with halothane $\left(1-3.5 \%\right.$ in a mixture of $70 \% \mathrm{~N}_{2} \mathrm{O}$ and $30 \%$ $\mathrm{O}_{2}$ ) using a face mask. The rectal temperature was maintained at $37 \pm$ $1^{\circ} \mathrm{C}$ throughout the surgical procedure using a feedback-regulated water heating system. The MCA was occluded by placement of an embolus at the origin of the MCA (Zhang et al., 1997). Briefly, a single intact fibrin-rich 24-hr-old homologous clot $(\sim 1 \mu \mathrm{l})$ was placed at the origin of the MCA via a $15 \mathrm{~mm}$ length of modified PE-50 catheter. All ischemic rats exhibited neurological deficits after MCA occlusion. Rats were killed at 1 and $4 \mathrm{hr}$ after MCA occlusion. Sham-operated rats were subjected to the same procedure without injecting a clot.

Tissue preparation. (1) Vibratome sections: $1(n=4)$ or $4 \mathrm{hr}(n=4)$ after MCA occlusion, fluorescein isothiocyanate (FITC) dextran $(2 \times$ $10^{6}$ molecular weight; Sigma, St. Louis, MO; $0.1 \mathrm{ml}$ of $50 \mathrm{mg} / \mathrm{ml}$ ) was administered intravenously. In addition, two sham-operated rats and two nonoperated rats received FITC-dextran as control groups. Shamoperated rats were killed at $4 \mathrm{hr}$ after sham operation. FITC-dextran remains dissolved and free in plasma (Morris et al., 1999; Zhang et al., 1999a). This dye circulated for $1 \mathrm{~min}$, after which the anesthetized animals were killed by decapitation. The brains were rapidly removed from the severed heads and placed in $4 \%$ of paraformaldehyde at $4{ }^{\circ} \mathrm{C}$ for $48 \mathrm{hr}$. Coronal sections $(100 \mu \mathrm{m})$ were cut on a vibratome. (2) Paraffin sections: $1(n=6)$ or $4(n=5)$ hr after placement of the embolus, animals were anesthetized (intramuscularly) with ketamine $(44 \mathrm{mg} / \mathrm{kg}$ ) and xylazine $(13 \mathrm{mg} / \mathrm{kg})$. Rats were transcardially perfused with heparinized saline and $10 \%$ buffered formalin, and brains were removed. Two sham-operated rats were killed at $4 \mathrm{hr}$ after sham operation and used as a control group. Using a rat brain matrix, each brain was cut into 2-mm-thick coronal blocks, for a total of seven blocks per animal. The brain tissue was processed, embedded, and $6-\mu \mathrm{m}$-thick paraffin coronal sections from each block were cut and stained with hematoxylin and eosin for histopathological evaluation. A 6- $\mu \mathrm{m}$-thick paraffin coronal section from the center of ischemic core (section $\mathrm{D}$; bregma, $-0.8 \mathrm{~mm}$ ) (Paxinos and Watson, 1986) was used for immunohistochemical staining and for in situ hybridization.

Immunohistochemistry. A goat anti-mouse fibrinogen/fibrin antibody was used at a titer of 1:1000 to assess the deposition of fibrin and fibrinogen-related antigen in brain (Accurate Chemical \& Scientific, Westbury, NY). Although this antibody detects both fibrin and fibrinogen, the titer of the antibody used in the present study primarily reacted with fibrin (Ploplis et al., 1995; Kitching et al., 1997). A rabbit anti-mouse PAI-1 antibody was used at a titer of 1:500 to assess the PAI-1 antigen (a gift from Dr. D. J. Loskutoff, The Scripps Research Institute, La Jolla, CA). A mouse monoclonal antibody to microtubule-associated protein-2 (MAP-2; clone AP20; Boehringer Mannheim. Indianapolis, IN) was used at a titer 1:50 for evaluation of early ischemic neuronal injury (Dawson and Hallenbeck, 1996; Z hang et al., 1999a). A rabbit polyclonal antibody against cow glial fibrillary acidic protein (GFAP) (1:400; Dako, Carpinteria, CA) was used for evaluation of astrocytes. The immunospecificities of MAP-2 and GFAP antibodies have been well demonstrated in rats (Garcia et al., 1994; Dawson and Hallenbeck, 1996).

Single immunofluorescence labeling was performed to measure fibrin deposition. Vibratome sections were incubated with the anti-fibrinogen antibody for $3 \mathrm{~d}$ at $4^{\circ} \mathrm{C}$, and sections were then incubated with the Cy5-conjugated anti-goat Ig antibody (Vector Laboratories, Burlingame, CA). Double immunofluorescence labeling for fibrin(ogen) and GFAP or fibrin(ogen) and MAP-2 was performed to simultaneously evaluate fibrin deposition and astrocytic reactivity or fibrin deposition and neuronal injury, respectively. Vibratome sections were incubated with the antibody against fibrinogen for $3 \mathrm{~d}$ at $4^{\circ} \mathrm{C}$, and sections were then incubated with the secondary antibody conjugated to Cy5. These vibratome sections were incubated with the antibody against GFAP or MAP- 2 for $3 \mathrm{~d}$ at $4{ }^{\circ} \mathrm{C}$ and then with the secondary antibody conjugated to $\mathrm{Cy} 3$. Because vibratome coronal sections were perfused with FITC dextran, red Cy3 and far red $\mathrm{Cy} 5$ fluorochromes were used for immunofluorescence doublelabeling. Control experiments consisted of staining brain coronal tissue sections as outlined above, but omitted the primary antibodies. Single immunofluorescence (GFAP or MAP-2)-stained sections were used to compare the staining patterns to those obtained in the double-stained sections.

Although the titer of the antibody against fibrinogen used in the present study primarily reacted with fibrin, contaminating fibrinogen may be a problem in nonperfused tissue. To further confirm the specificity of this antibody for fibrin, immunostaining for fibrin(ogen) was performed on an additional set of rats that were extensively perfused as indicated above. Coronal sections from paraffin-embedded tissue $(6 \mu \mathrm{m})$ were incubated with the anti-fibrinogen antibody for $1 \mathrm{hr}$ at room temperature. The immunoreactivity was visualized with diaminobenzidine.

Immunohistochemical staining for PAI-1 was performed on coronal sections (6- $\mu \mathrm{m}$-thick) from paraffin-embedded tissue. The coronal sections were incubated with the anti-PAI-1 antibody for $1 \mathrm{hr}$ at room temperature. The sections were then incubated with biotinylated rabbit anti-goat IgG (Vector Laboratories). The immunoreactivity was visualized with diaminobenzidine.

In situ hybridization. The 562 bp mouse cDNA of PAI-1 was used as a probe for in situ hybridization (a gift from Dr. D. Belin, University of Geneva, Geneva, Switzerland) (Sappino et al., 1993). In situ hybridization was performed using a digoxigenin DNA labeling and detection kit (Boehringer Mannheim) according to manufacturer's protocol. Briefly, after deparaffinizing, coronal sections $(6 \mu \mathrm{m})$ were digested by proteinase $\mathrm{K}(100 \mu \mathrm{g} / \mathrm{ml})$ for $15 \mathrm{~min}$ at $37^{\circ} \mathrm{C}$ and were fixed by $10 \%$ formaldehyde for $5 \mathrm{~min}$ at $4^{\circ} \mathrm{C}$. Prehybridization solution containing $4 \times \mathrm{SSC}, 50 \%$ deionized formamide, $1 \times$ Denhardt's solution, $0.5 \mathrm{mg} / \mathrm{ml}$ of salmon sperm DNA, $10 \%$ dextran sulfate, and $0.25 \mathrm{mg} / \mathrm{ml}$ yeast tRNA was applied for $1 \mathrm{hr}$ at room temperature. Denatured digoxigenin-labeled cDNA probe concentration for hybridization was $750 \mathrm{ng} / \mathrm{ml}$. Coronal sections were incubated under coverslips overnight at $42^{\circ} \mathrm{C}$ with hybridization solution in a humidified chamber. Posthybridization stringency washes at room temperature included $2 \times$ SSC for $1 \mathrm{hr}, 1 \times$ SSC for $1 \mathrm{hr}$, and $0.5 \times$ SSC for $1 \mathrm{hr}$. After treatment with $2 \%$ of normal sheep serum, hybridization probe was detected by anti-digoxigen antibody conjugated to alkaline phosphatase at 1:500 dilution for $3 \mathrm{hr}$ at room temperature. Nitroblue tetrazolium/5-bromo-4-chloro-3-indolyl phosphate solution was used as a color substrate. Color reaction time was $20 \mathrm{hr}$. Sections were dehydrated in a graded series of ethanol and mounted.

Three-dimensional image acquisition. The vibratome sections were analyzed with a Bio-Rad (Cambridge, MA) MRC 1024 (argon and krypton) laser-scanning confocal imaging system mounted onto a Zeiss microscope (Bio-Rad). With the FITC-perfused tissue samples from each rat, 10 vibratome sections from interaural $6.38 \mathrm{~mm}$ to interaural $1.00 \mathrm{~mm}$ (Paxinos and Watson, 1986) at $2 \mathrm{~mm}$ interval were screened under a $10 \times$ objective lens, and the ones that showed the greatest contrast in the plasma marker distribution, presumably the result of the placement of the embolic clot, were selected from each animal. Immunofluorescent staining and analysis were performed on the adjacent sections from the selected section. For sections stained with the anti-fibrinogen antibody (Cy5), green (FITC-dextran perfused microvessels) and far red [Cy5, fibrin(ogen) immunoreactivity] fluorochromes on the sections were excited by a laser beam at 488 and $647 \mathrm{~nm}$; emissions were simultaneously acquired with two separate photomultiplier tubes through 522 and 680 $\mathrm{nm}$ emission filters, respectively. For sections stained with both GFAP (Cy3) and fibrinogen (Cy5) antibodies, or MAP-2 (Cy3) and fibrinogen (Cy5), green (FITC-dextran perfused microvessels), red (Cy3, GFAPimmunoreactive astrocytes or MAP-immunoreactive neurons) and far red [Cy5, fibrin(ogen) immunoreactivity] fluorochromes on the sections were excited by a laser beam at 488, 568, and $647 \mathrm{~nm}$, respectively. Optical emissions were sequentially detected with a photomultiplier tube through 522, 585, and $680 \mathrm{~nm}$ emission filters, respectively. Because the size of the fluorescent spots in a two-dimensional image depends on the laser power, iris, gain, and duration of sampling time, these parameters were fixed within the same section during the acquisition of data. Areas of interest on the ipsilateral and homologous areas on the contralateral side were scanned with a $40 \times$ oil-immersion objective lens with a numerical aperture of 1.3 in $512 \times 512$ pixel $(260.6 \times 260.6 \mu \mathrm{m})$ format in the $x-y$ direction using a $4 \times$ frame-scan average. Twenty thin optical sections along the $z$-axis with $1 \mu \mathrm{m}$ step size were acquired. The tissue volume or image size was $260.6 \times 260.6 \times 20 \mu \mathrm{m}^{3}$. Four fields of view from low FITC-dextran-perfused regions in the subcortex and three fields from the cortex in the reference section were randomly selected. A total of 112 images were acquired from nonoverlapping fields.

Three-dimensional image analysis and reconstruction. To quantify 
FITC-dextran and fibrin(ogen) immunoreactivity in tissue samples, all FITC-dextran and fibrin(ogen)-immunoreactive images acquired from the LSCM were analyzed with The Microcomputer Imaging Device (Imaging Research, St. Catherines, Ontario, Canada) image analysis system, as previously reported (Morris et al., 1999; Zhang et al., 1999a). Briefly, a single composite three-dimensional image $(260.6 \times 260.6 \times 20$ $\mu \mathrm{m}^{3}$ ) was reconstructed from the distribution of FITC-dextran or fibrin(ogen) immunoreactivity. Because the $z$-step position was kept intact, the resulting reconstructions covered identical tissue volumes and could be overlaid to produce composite images. A fixed grayscale display cutoff of 60 for FITC-dextran or 150 for fibrin(ogen) immunoreactivity was then applied to the model to ensure that the three-dimensional reconstruction was an accurate rendering of the original tissue-staining pattern. The choice of a cutoff value of 60 for FITC-dextran was based on our previous studies (Morris et al., 1999; Zhang et al., 1999a). A cutoff value of 150 for fibrin(ogen) immunoreactivity was based on preliminary image analysis data. We used a series of cutoff values (20-200) for fibrin(ogen) immunoreactivity in our preliminary analysis and found that a cutoff value of 150 most faithfully reflects the original images. The total volume of staining present in the rendered cube of tissue was then calculated in cubic micrometers and divided by the total tissue volume to determine the percentage of tissue volume that was fluorescently marked.

To eliminate low-frequency variations in gray scale value in two dimensions and small size noise in three dimensions, all GFAPimmunoreactive images acquired from the LSCM were analyzed using Eigentool image analysis software on a SUN UltraSPARC2 workstation (SUNvision). Eigentool software, developed by the Image Analysis Laboratory at Henry Ford Hospital, has a comprehensive set of functions for analyzing images in two and three dimensions (Windham et al., 1988; Soltanian-Zadeh and Windham, 1994). After the volume was thresholded by a gray level of 120 , three-dimensional objects were determined from the remaining voxels. A voxel was included in an object if a face, side, edge, or corner touched any voxel already in that object. The size of a three-dimensional object was the number of voxels contained in the object. All three-dimensional objects with fewer than two voxels were eliminated from further analysis (Zhang et al., 1999b). The measurement of GFAP immunostaining present in tissue was simply the number of voxels remaining in the volume. Data are presented as a percentage of volume, in which the number of GFAP-immunostained voxels was divided by the total number of voxels in the volume. These thresholds eliminate noise and do not alter the original signals (Zhang et al., 1999b). Binary images were generated from subimaging of GFAPimmunoreactive volume. These binary images were imported to the MCID image analysis system for constructing three-dimensional images.

Quantitation of PAI-1 $\mathrm{mRNA}$ and PAI-1-immunoreactive vessels. Each PAI-1-immunostained and PAI-1-hybridized coronal section was digitized under a 20 or $40 \times$ objective (BX40; Olympus Optical, Tokyo, Japan) for measurement of the number of PAI-1 mRNA and PAI-1 immunoreactive vessels and diameters of the vessels using a three-CCD color video camera (DXC-970MD; Sony, Tokyo, Japan) interfaced with an MCID image analysis system. Numbers of vessels exhibiting PAI-1 mRNA and PAI-1 immunoreactivity were counted throughout the brain, and the maximum diameter (the maximum internal distance perpendicular to the maximum curved chord) of these vessels was measured using the MCID system. Vessels were categorized by their diameters as: capillary $(<7.5 \mu \mathrm{m})$, precapillary arterioles and postcapillary venules $(>7.6-30 \mu \mathrm{m})$, and small arterioles and connecting vessels $(>31-50 \mu \mathrm{m})$ (del Zoppo, 1994).

Statistical analysis. ANOVA followed by $t$ tests with Bonferroni correction were used to compare control, 1 , and $4 \mathrm{hr}$ groups. All data are presented as mean $\pm \mathrm{SE}$, and $p<0.05$ was considered statistically significant.

\section{RESULTS \\ Distribution of fibrin(ogen) immunoreactivity and cerebral microvascular plasma perfusion}

To examine whether deposition of fibrin directly obstructs cerebral microvascular plasma perfusion, distribution of FITCdextran-filled cerebral microvessels and Cy5-labeled fibrin(ogen) immunoreactivity was measured in three dimensions in the control and the embolic ischemic animals. FITC-dextran-filled microvessels in $x-y$ projections exhibited an irregular and tortuous pattern in the sham-operated and nonsurgical brains (Fig. 1A, green). Intravascular blood cells were visible as dark oval figures filling the microvascular lumina between the intraluminal FITCdextran (Fig. 1A). Fibrin(ogen) immunoreactivity was not detected in the control rat brains (Fig. $1 B$ ). In contrast, $1 \mathrm{hr}$ after MCA occlusion, large areas of little or no FITC-dextran were primarily detected in the ipsilateral subcortex (Fig. 1D, green) and occasionally in the piriform cortex, suggesting nonperfused and underperfused tissue. An irregular tubular pattern of fibrin(ogen) immunoreactivity was observed in the areas with little or no FITC-dextran and extended to the areas with intraluminal FITC-dextran (Fig. 1E, red). Fibrin(ogen) immunoreactivity was not detected in the ischemic lesion when the primary antibody was omitted (Fig. 1G). Intraluminal FITC-dextran terminated abruptly within cerebral microvessels (Fig. 1D, green). Examination of this region under high-power magnification revealed intense fibrin(ogen) immunoreactivity (Fig. $1 \mathrm{~J}-\mathrm{O}$, red) proximal to intraluminal FITC-dextran (Fig. $1 J-O$, green) in $x-y, x-z$, and $y-z$ projections, indicating that intravascular deposition of fibrin locally blocked perfusion of FITC-dextran. In addition, threedimensional reconstructions revealed that intravascular fibrin(ogen) immunoreactivity partially blocked intraluminal FITCdextran perfusion upstream within relatively large vessels and led to complete obstruction of FITC-dextran perfusion downstream vessels (Fig. $2 A, B$ ). To further confirm the possible intravascular deposition of fibrin observed on three-dimensional images, fibrin(ogen) immunohistochemistry was performed on coronal sections from the extensively perfused brain tissue. Intravascular fibrin(ogen)-immunoreactive meshwork was also observed on veins (Fig. 2C,D) and capillaries (Fig. 2E) in extensively perfused brain tissue after $1 \mathrm{hr}$ of MCA occlusion. Erythrocytes, polymorphonuclear (PMN) leukocytes, and platelets were attached to fibrin by multiple connections, and aggregated platelets were enmeshed in fibrin (Fig. $2 C-E$ ).

At $4 \mathrm{hr}$ of MCA occlusion, the areas with little and no FITCdextran in subcortex expanded to the cortex supplied by the MCA, and expansion of underperfused FITC-dextran areas was accompanied by an increase in fibrin(ogen) immunoreactivity. In addition to intravascular fibrin(ogen) immunoreactivity as seen at $1 \mathrm{hr}$ of embolic stroke, three-dimensional reconstruction revealed massive irregular shapes of fibrin(ogen) immunoreactivity in the areas with no FITC-dextran in the subcortex (Fig. $2 F$, red), suggesting the presence of fibrin deposition in the parenchyma. To further confirm fibrin deposition, immunohistochemistry of fibrin(ogen) was performed on extensively perfused brain tissue. The fibrin(ogen)-immunoreactive meshwork in the subcortical parenchymal tissue colocalized with shrunken neurons and activated astrocytes in perfused brain tissue (Fig. 2G). This staining pattern was comparable to that seen in three-dimensional images, confirming deposition of fibrin in the parenchyma. The parenchymal fibrin(ogen) immunoreactivity was primarily detected in the subcortex. The intravascular fibrin(ogen) immunoreactivity was present in areas of the piriform and parietal cortex supplied by the MCA (Fig. 2H). These areas exhibited mixtures of non FITC-dextran, FITC-dextran perfusion, and fibrin(ogen) immunoreactivity (Fig. $2 H$ ).

To obtain quantitative data on levels of FITC-dextran and fibrin(ogen) immunoreactivity, we measured FITC-dextran and Cy5-fibrin(ogen) immunoreactivity in three-dimensional images obtained from LSCM. Values of FITC-dextran were 1.7 and $0.7 \%$ for the control cortex and subcortex (Fig. 2A,B), respectively, which are above previously published data $(0.74-0.86 \%$ for 
Figure 1. Fibrin deposition and cerebral microvascular plasma perfusion from LSCM. Two-dimensional images $(x-y$ projections, $260.6 \times 260.6$ $\mu \mathrm{m}^{2}$ ) through the stack of 20 optical sections $(1 \mu \mathrm{m} /$ section $)$ of plasma perfusion in capillary networks and fibrin(ogen) immunoreactivity in the ipsilateral caudate putamen from a sham-operated control rat $(A-C)$ and from a rat subjected to $1 \mathrm{hr}$ of embolic MCA occlusion $(D-I)$. Plasma perfusion indicated by intraluminal FITCdextran shows green color, and fibrin immunoreactivity exhibits red color. $A$, $D$, and $G$ are merged images from red $(B, E$, and $H)$ and green $(C, F$, and $I)$. The plasma-demarcated capillary networks show a broad array of twist, turns, and junctions in the caudate putamen from a sham-operated rat $(A$, $C)$. The absence of plasma perfusion (green) in the ipsilateral caudate putamen and increase of fibrin(ogen) immunoreactivity (red) are obvious at 1 hr of embolic MCA occlusion $(D-F)$. Fibrin(ogen) immunoreactivity (red) was not detected when primary antibody was omitted on an adjacent section $(G-I)$. High magnification of three-dimensional reconstructions $(J-O$, $130.3 \times 130.3 \times 40 \mu \mathrm{m}^{3}$ ) of plasma perfusion in capillary networks and fibrin(ogen) immunoreactivity from the region in $D . J$ is a merged image before three-dimensional rendering, and $\mathrm{K}-\mathrm{O}$ are images rendered in threedimensional space through a stack of 40 optical sections $(1 \mu \mathrm{m} / \mathrm{section}) . K$ is at $x=0$, and $y=0 ; L$ is at $x=0$, and $y=$ $180 ; M$ is at $x=270$, and $y=0 ; N$ is at $x=270$, and $y=90 ; O$ is at $x=290$, and $y=30$. Fibrin deposition (red) directly obstructs plasma perfusion (green), as indicated by arrow and arrowhead.
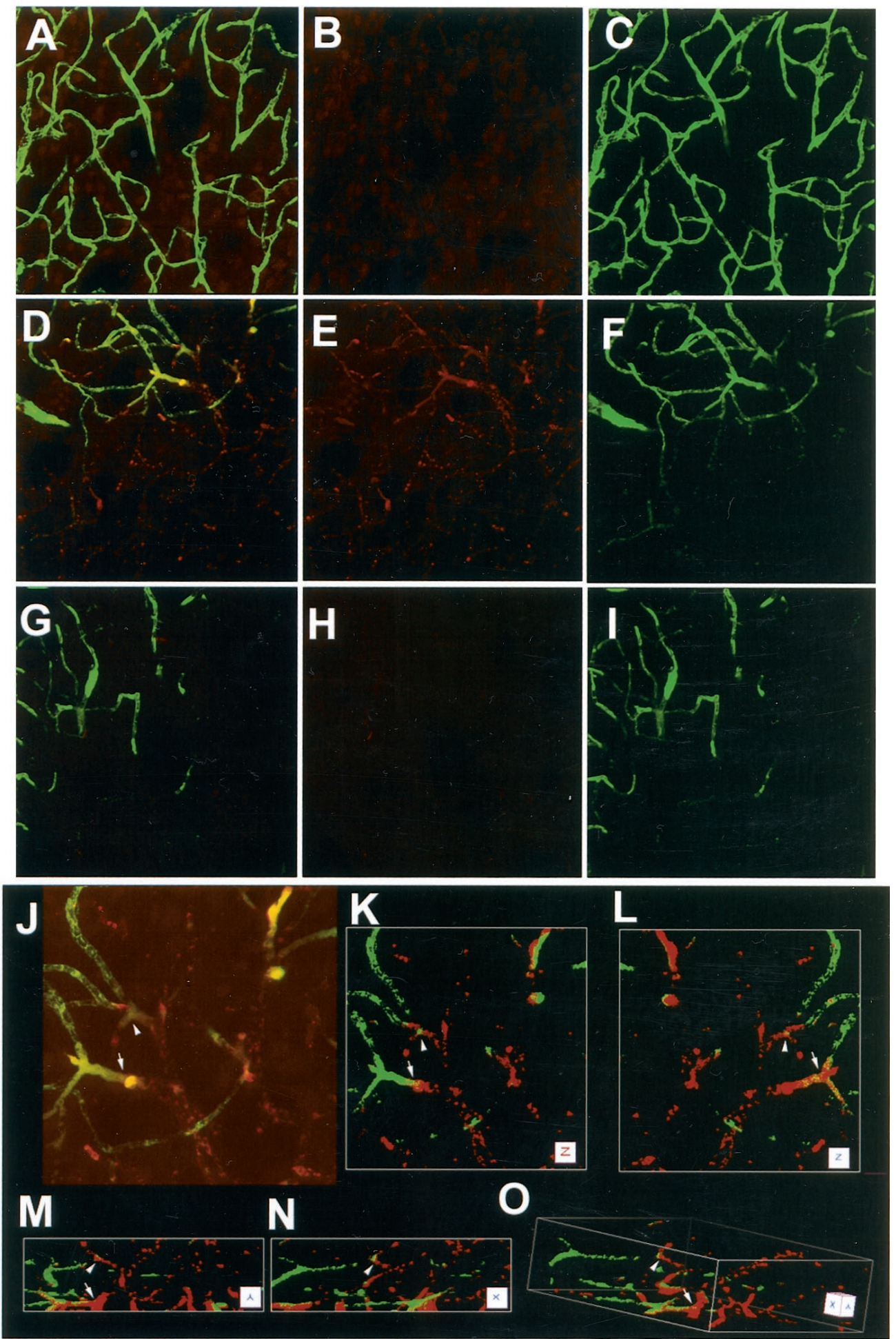

cortex and $0.44-0.66 \%$ for the sucbcortex) (Berecki, 1992; Zhang et al., 1999a). The reason for these high values is that some images obtained from homologous tissue in the contralateral hemisphere contained large vessels, as indicated in Figure 2, $A$ and $B$. If we exclude these large vessels, values of FITC-dextran were $1.1 \%$ for the cortex and $0.6 \%$ for the subcortex. A significant $(p<0.05)$ reduction of FITC-dextran was accompanied by a significant increase in fibrin(ogen) immunoreactivity in the ipsilateral subcortex at 1 and $4 \mathrm{hr}$ and in the ipsilateral cortex at $4 \mathrm{hr}$ after embolic stroke, compared with the homologous tissue in the contralateral hemisphere (Fig. 3A,B, respectively). Although a reduction in plasma perfusion and an increase in fibrin(ogen) immunoreactivity were detected in the ipsilateral cortex, differences between the ipsilateral and the contralateral cortex were not statistically significant at $1 \mathrm{hr}$ after MCA occlusion. However, fibrin(ogen) immunoreactivity was significantly $(p<0.01)$ higher in the ipsilateral cortex at $4 \mathrm{hr}$ than fibrin(ogen) immunoreactivity at $1 \mathrm{hr}$ after MCA occlusion (Fig. $3 A, B$ ). We also measured 

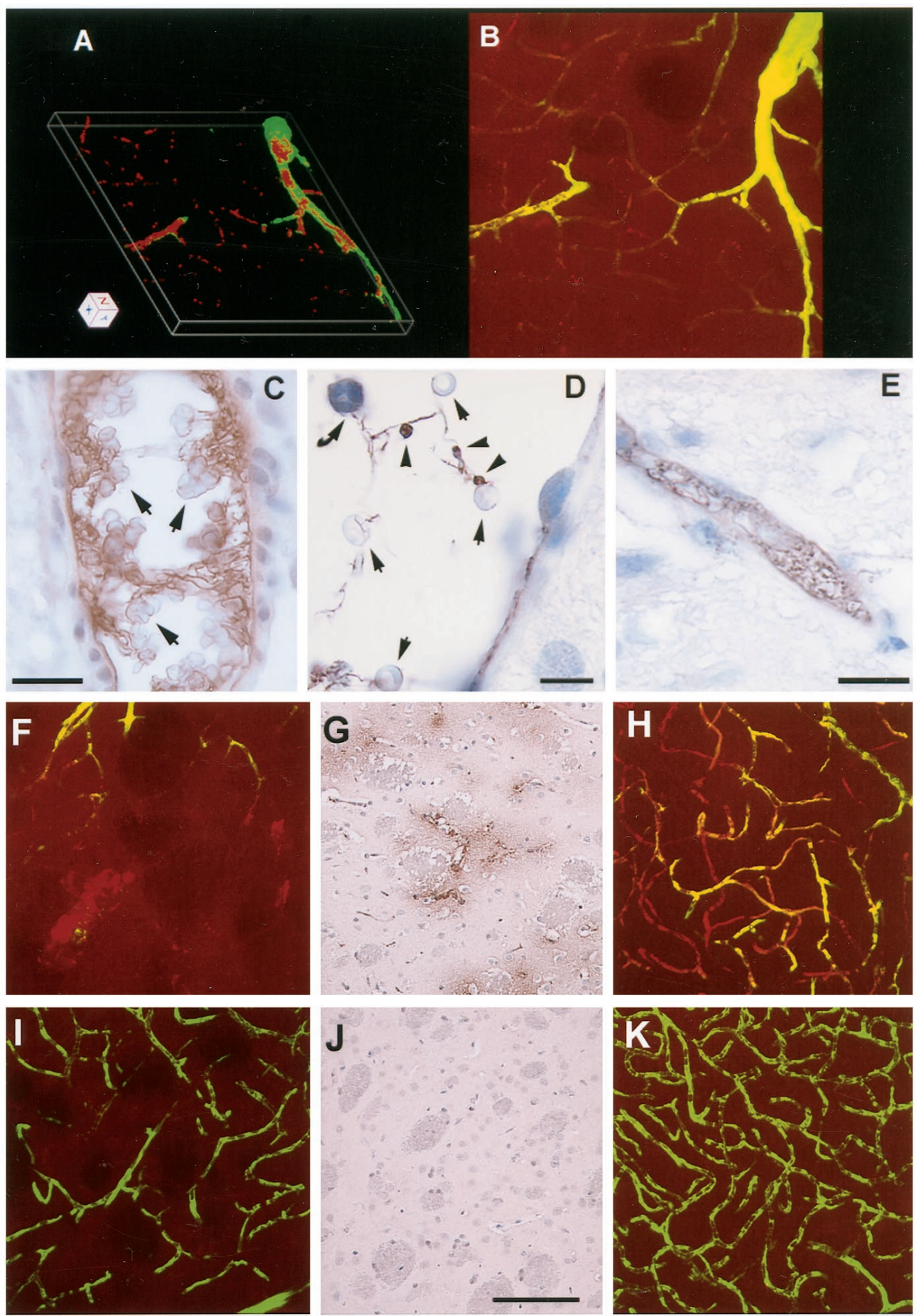

E
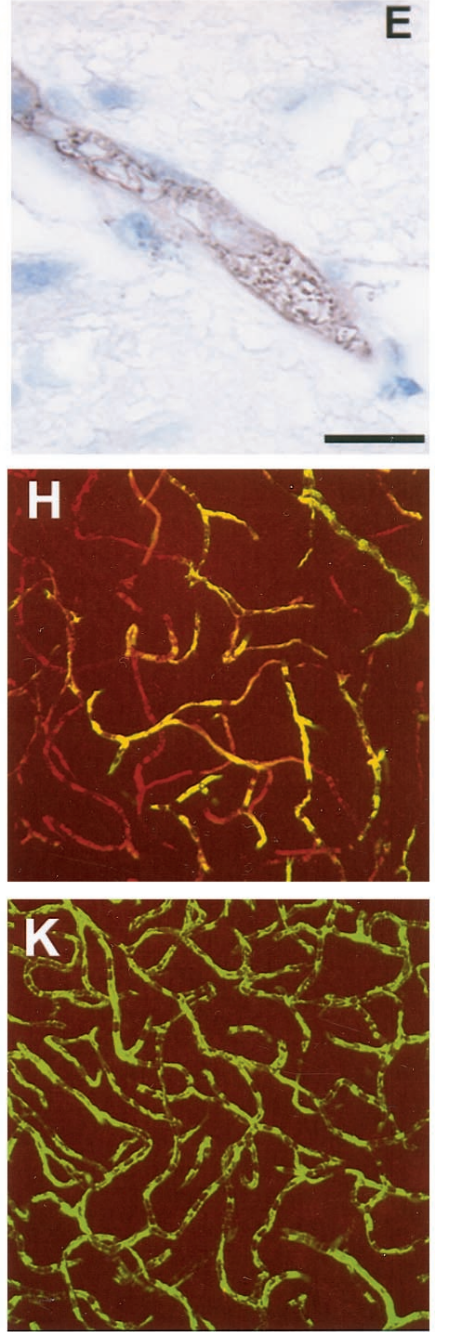

Figure 2. Intravascular fibrin deposition, erythrocytes, PMN leukocytes, and platelets from rats subjected to 1 hr of embolic MCA occlusion. $A$ is a three-dimensional reconstructed image $\left(260.6 \times 260.6 \times 20 \mu \mathrm{m}^{3}\right)$ through a stack of 20 optical sections $(1 \mu \mathrm{m} /$ section) of plasma perfusion and fibrin(ogen) immunoreactivity from $B$, which is a merged image. Intravascular fibrin deposition in a relative large vessel causes the vessel to narrow and decreases plasma perfusion in capillaries $(A, B)$. Erythrocytes (arrows), PMN leukocytes (curved arrow), and platelets (arrowheads) were connected with fibrin within venules $(C, D)$ and capillaries $(E)$ in the ipsilateral caudate putamen from extensively perfused brain tissue. $F, H, I$, and $K$ are images $(x-y$ projections, $260.6 \times 260.6$ $\mu \mathrm{m}^{2}$ ) through the stack of 20 optical sections $(1 \mu \mathrm{m} /$ section $)$ of plasma perfusion in capillary networks (green) and fibrin(ogen) immunoreactivity (red) in the ipsilateral caudate putamen $(F)$ and in the ipsilateral cortex $(H)$ from a rat subjected to $4 \mathrm{hr}$ of embolic MCA occlusion. Fibrin(ogen) immunoreactivity (red) was present in extravascular space with little plasma perfusion ( $F$, green $)$, and fibrin(ogen) immunoreactivity was not present in the homologous tissue of the contralateral hemisphere $(I)$. Parenchymal fibrin deposition was also observed in the ipsilateral caudate putamen $(G)$ but not the homologous area of the contralateral hemisphere $(J)$ from extensively perfused brain tissue at $4 \mathrm{hr}$ of MCA occlusion. Mixture $(H$, yellow $)$ of microvascular plasma perfusion $(H$, green $)$ with intravascular fibrin deposition $(H, r e d)$ was detected in the ipsilateral parietal cortex $(H)$ compared with the contralateral homologous tissue $(K$, green only). Scale bars: $D, 10 \mu \mathrm{m} ; C, E, 20$ $\mu \mathrm{m} ; G, J, 100 \mu \mathrm{m}$. numbers of vessels that were fibrin(ogen)-immunoreactive under light microscopy (Table 1$)$. A significant $(p<0.05)$ increase of intravascular fibrin(ogen) immunoreactivity was also detected in the cortex and the subcortex at 1 and $4 \mathrm{hr}$ after stroke compared with the contralateral hemisphere. Numbers of intravascular fibrin(ogen)-immunoreactive vessels were significantly $(p<0.05)$ increased in the ipsilateral cortex at $4 \mathrm{hr}$ after ischemia compared with the 1 hr group. Numbers of vessels with extravascular fibrin deposition were significantly $(p<0.05)$ higher in the subcortex at $4 \mathrm{hr}$ after ischemia than at $1 \mathrm{hr}$ and the control group (Table 1).

To examine neuronal response to plasma perfusion deficits and fibrin deposition, MAP-2 immunoreactivity was examined along with FITC-dextran and fibrin(ogen) immunoreactivity. Triple fluorescence in the $x-y$ projections revealed that intense fibrin(ogen) immunoreactivity (Fig. $4 A$, red) was present in areas of low MAP-2 immunoreactivity (Fig. 4A, blue) and little or no FITCdextran (Fig. $4 A$, green) compared with the homologous tissue in the contralateral hemisphere (Fig. 4B). Analysis of extensively perfused brain tissue under light microscopy revealed that acute ischemic neuronal injury, dark neurons, were present adjacent to vessels with fibrin deposition at $1 \mathrm{hr}$ after embolic stroke (Fig. 4C, arrowhead). At $4 \mathrm{hr}$ after stroke, the subcortical areas with intravascular fibrin deposition exhibited increased numbers of shrunken neurons (Fig. 4D, arrowheads), swollen astrocytes (Fig. 
Figure 3. Bar graphs show volumes of cerebral microvascular plasma (open bars) and fibrin(ogen) immunoreactivity ( filled bars) in the cortex $(A)$ and the subcortex $(B)$ at 1 and $4 \mathrm{hr}$ after embolic MCA occlusion. Control = homologous tissue in the contralateral hemisphere. ${ }^{*} p<0.05$, significantly different from the control group; ${ }^{* *} p<0.01$, significantly different from the control group; and $+p<$ 0.01 , significantly different from $1 \mathrm{hr}$ group.
A

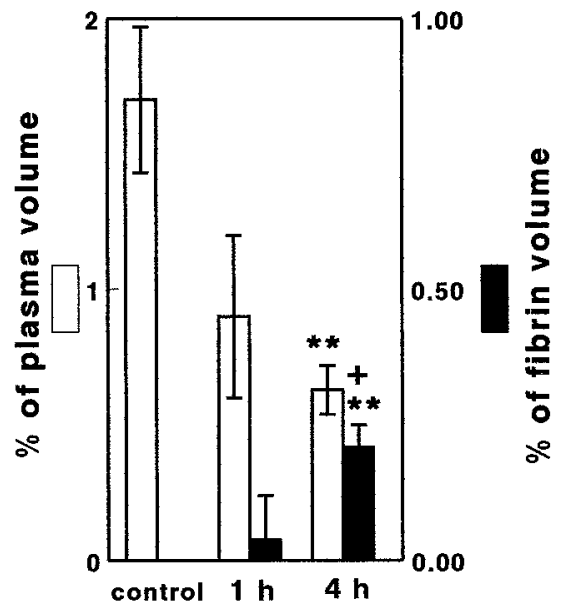

B

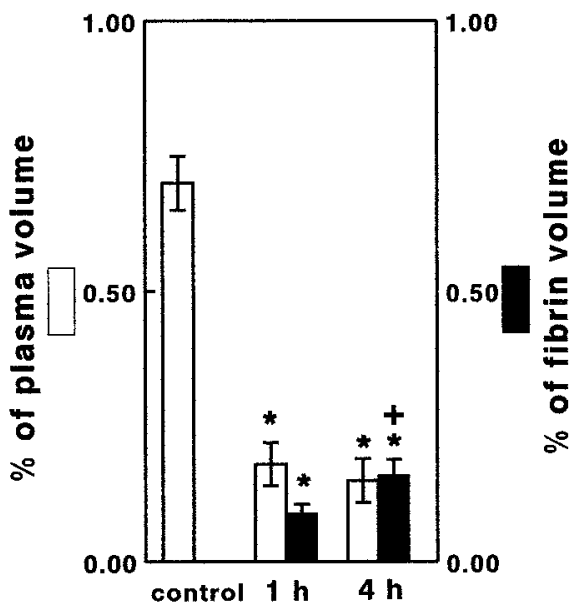

Table 1. Fibrin deposition in ischemic brain after embolic MCA occlusion

\begin{tabular}{|c|c|c|c|c|c|c|c|c|}
\hline \multirow[b]{3}{*}{ Groups } & \multicolumn{4}{|c|}{ Numbers of vessel with intravascular fibrin deposition } & \multicolumn{4}{|c|}{ Numbers of vessels with extravascular fibrin deposition } \\
\hline & \multicolumn{2}{|l|}{ Cortex } & \multicolumn{2}{|l|}{ Subcortex } & \multicolumn{2}{|c|}{ Cortex } & \multicolumn{2}{|l|}{ Subcortex } \\
\hline & Ipsi. & Contra. & Ipsi. & Contra. & Ipsi. & Contra. & Ipsi. & Contra. \\
\hline $1 \mathrm{hr}(n=6)$ & $145 \pm 45.9^{*}$ & 0 & $202 \pm 121.67^{*}$ & 0 & 0 & 0 & 0 & 0 \\
\hline $4 \mathrm{hr}(n=5)$ & $408 \pm 112.74 * * *$ & 0 & $417 \pm 88.36^{*}$ & 0 & 0 & 0 & $158 \pm 76.26^{*}, * *$ & 0 \\
\hline control $(n=2)$ & 0 & 0 & 0 & 0 & 0 & 0 & 0 & 0 \\
\hline
\end{tabular}

\footnotetext{
All values are mean \pm SE.

*Significantly $(p<0.05)$ different from the control group and from the contralateral hemisphere.

**Significantly $(p<0.05)$ different from the $1 \mathrm{hr}$ embolic ischemic group.

Ipsi., Ipsilateral hemisphere; Contra., contralateral hemisphere.
}

$4 D$, arrow), and vacuoles. The subcortical areas with extravascular fibrin deposition showed shrunken neurons (Fig. 4E, arrowhead), increased vacuoles, and degeneration of cells (Fig. 4E) compared with the homologous areas in the contralateral hemisphere (Fig. $4 F$ ). In contrast, in the cortex, intravascular fibrin(ogen) immunoreactivity was detected in the areas with shrunken neurons adjacent to morphologically intact neurons (Fig. 4G, arrowheads).

\section{Distribution of GFAP immunoreactivity}

Activated astrocytes may contribute to microvascular impairment after focal cerebral ischemia (Hossmann, 1990).To examine whether activated astrocytes are involved in reduction of FITCdextran perfusion, FITC-dextran, GFAP, and fibrin(ogen) immunoreactivity were simultaneously measured in three dimensions at $1 \mathrm{hr}$ after MCA occlusion. GFAP immunoreactivity (Fig. $4 I$, blue) increased in areas with little or no FITC-dextran (Fig. $4 I$, green) and with increase of fibrin(ogen) immunoreactivity (Fig. 4I, red) when compared with the contralateral homologous areas (Fig. $4 J$ ). Although increased GFAP immunoreactivity surrounds microvessels with little FITC-dextran (Fig. 4I, blue), fibrin(ogen) immunoreactivity directly blocked FITC-dextran perfusion (Fig. $4 K$, red, arrows). Quantitative data (Fig. 5) show a significant $(p<0.05)$ reduction of FITC-dextran perfusion and significant increases in GFAP and fibrin(ogen) immunoreactivity in the subcortex compared with the homologous tissue in the contralateral hemisphere after $1 \mathrm{hr}$ of MCA occlusion.

\section{PAI-1 mRNA and PAI-1 immunoreactivity}

PAI-1 mRNA was not detected in the brain tissue from shamoperated and nonoperated rats and in the contralateral hemisphere of ischemic rats examined by in situ hybridization (Fig. $6 D)$. A hybridization signal for PAI-1 mRNA was detected in cells that had the appearance of endothelial cells and lined the surfaces of the vascular lumina in the ischemic lesion (Fig. 6A, arrows). Dense PAI-1 immunoreactivity appeared in the endothelial cytoplasm on venules (Fig. 6B, arrows) and capillaries (Fig. $6 C$, arrow) in the ischemic areas. To obtain quantitative data on levels of PAI-1 mRNA and PAI-1 antigen, we measured number of vessels and diameters of vessels that contained PAI-1 mRNA or PAI-1 immunoreactivity. Numbers of vessels that expressed PAI- 1 mRNA were $4 \pm 0.5$ and $20 \pm 12$ in the ipsilateral subcortex at 1 and $4 \mathrm{hr}$ of embolic MCA occlusion, respectively, and $0 \pm 0$ and $8 \pm 2.6$ in the cortex at 1 and $4 \mathrm{hr}$ of ischemia, respectively. Numbers of vessels with PAI-1 immunoreactivity significantly increased in the ipsilateral subcortex $(45 \pm 9.0)$ and cortex $(23 \pm 7.9)$ at $4 \mathrm{hr}$ when compared with number of vessels in the ipsilateral subcortex $(3 \pm 0.5)$ and cortex $(0 \pm 0)$ at $1 \mathrm{hr}$ of embolic MCA occlusion. Seventy percent of PAI-1-immunoreactive cerebral vessels had a mean diameter of $19.1 \pm 3.02 \mu \mathrm{m}$, $29 \%$ had a mean diameter of $5.2 \pm 0.8 \mu \mathrm{m}$, and $1 \%$ had a mean diameter of $32 \pm 2.8 \mu \mathrm{m}$, suggesting increases in PAI-1 primarily localize in precapillary arterioles, postcapillary venules, and capillaries (del Zoppo, 1994). 

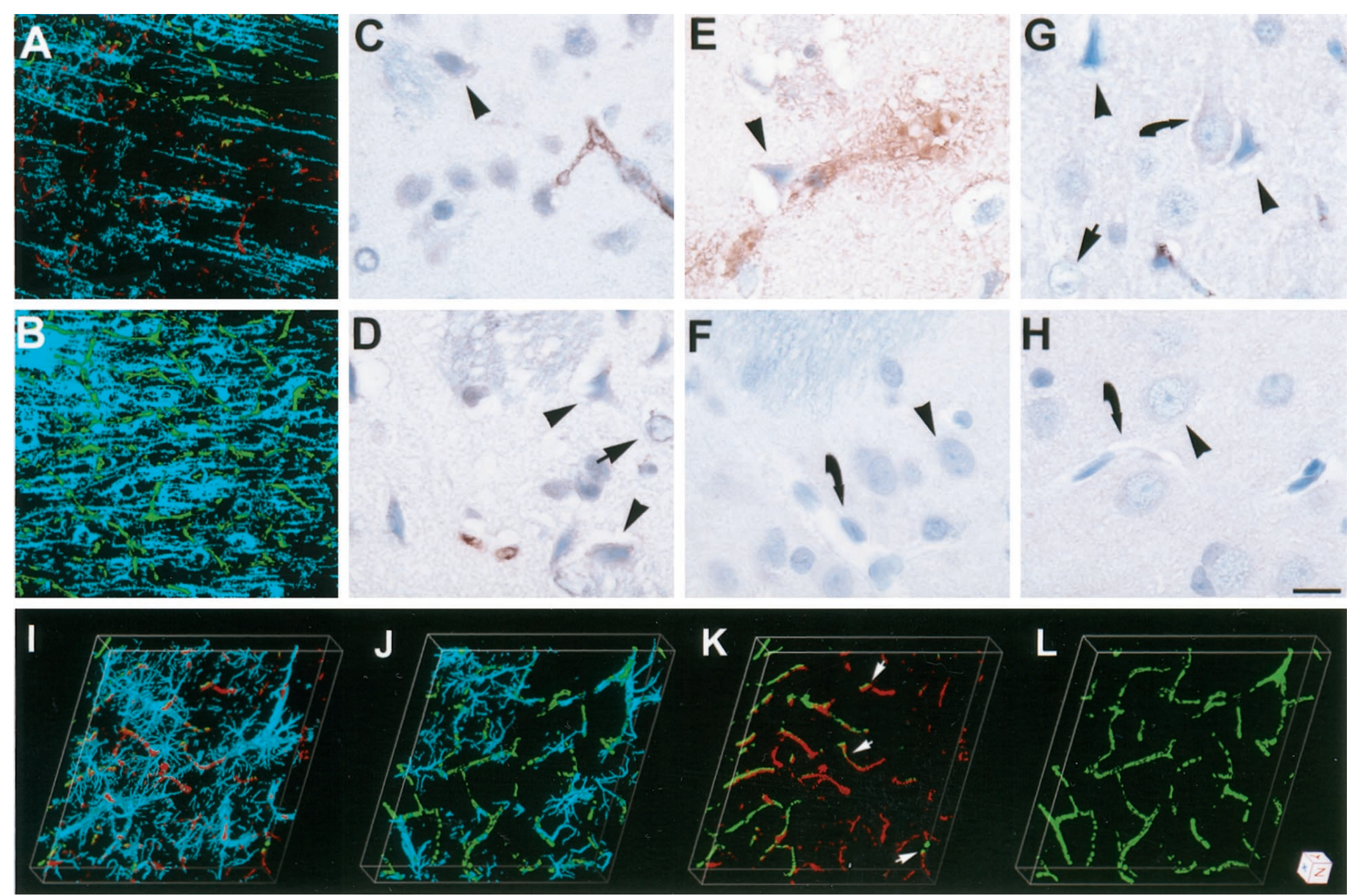

Figure 4. Fibrin deposition and ischemic cell damage. $A$ and $B$ are images $\left(x-y\right.$ projections, $\left.260.6 \times 260.6 \mu \mathrm{m}^{2}\right)$ through the stack of 20 optical sections $(1 \mu \mathrm{m} / \mathrm{section})$ of plasma perfusion in capillary networks (green), fibrin(ogen) immunoreactivity (red), and MAP-2 immunoreactivity (blue) from a rat subjected to $1 \mathrm{hr}$ of MCA occlusion. Increase in fibrin(ogen) immunoreactivity $(A$, red $)$ and loss of plasma perfusion $(A$, green) and MAP-2 immunoreactivity $(A$, blue $)$ on the ipsilateral hemisphere are evident $(A)$ compared with the contralateral hemisphere $(B)$. Dark neurons $(C$, arrowhead), shrunken neurons $(D$, arrowheads), and swollen astrocytes $(D$, arrow) were present in the striatum with intravascular fibrin deposition from extensively perfused brains at $1(C)$ and $4(D)$ hr of embolic MCA occlusion. Shrunken neurons (arrowhead) with vacuoles were present in the striatum with extravascular fibrin deposition $(E)$ compared with intact neurons (arrowhead) in the contralateral striatum with patent vessels (curved arrow) at 4 hr of embolic MCA occlusion $(F)$. Shrunken neurons (arrowheads), intact neurons (curved arrow), and swollen astrocytes (arrow) were present in the cortex with intravascular fibrin deposition $(G)$ compared with intact neurons (arrowhead) in the contralateral cortex with patent vessels (curved arrow) at 4 hr of ischemia $(H)$. I-L are three-dimensional reconstructions of microvascular plasma perfusion ( green), fibrin(ogen) immunoreactivity (red), and GFAP immunoreactivity (blue) in the caudate putamen from a rat subjected to $1 \mathrm{hr}$ of embolic stroke. Enlargement of GFAP-immunoreactive cell bodies and processes (blue) surrounded vessels (green) in the ischemic region $(I)$ compared with the homologous tissue in the contralateral hemisphere $(J)$. Microvascular plasma perfusion ( $K$, green, arrows) was directly blocked by fibrin deposition $(K$, red, arrows) when GFAP immunoreactivity was removed $(K, L)$. The image size is $260.1 \times 260.1 \times 20 \mu \mathrm{m}^{3}$ for $I-K$. Scale bar: $C-H, 10 \mu \mathrm{m}$.

\section{DISCUSSION}

To directly address whether fibrin deposition obstructs cerebral microvascular plasma perfusion, we simultaneously measured in three dimensions microvascular plasma perfusion and fibrin deposition in ischemic brain at 1 and $4 \mathrm{hr}$ of embolic MCA occlusion using intravascular fluorescent tracer molecules and immunofluorescent staining in combination with LSCM. The time points of 1 and $4 \mathrm{hr}$ chosen in the present study were based on our previous studies in this model that a progressive cerebral microcirculatory impairment is present during this period (Zhang et al., 1997, 1999a; Morris et al., 1999). Three-dimensional reconstructions demonstrate that fibrin deposition not only directly obstructed microvascular plasma perfusion, primarily within capillaries of the ischemic core, but that fibrin was also present within plasmaperfused vessels bordering the ischemic core at $1 \mathrm{hr}$ after MCA occlusion. The marked increase of intravascular fibrin deposition in the cortex and appearance of extravascular fibrin deposition in the striatum were associated with reduction of cerebral microvascular plasma perfusion at $4 \mathrm{hr}$ of ischemia. This threedimensional assessment was confirmed by measuring numbers of fibrin(ogen)-immunoreactive vessels on immunohistochemically stained sections. Numbers of vessels with intravascular fibrin deposition in the cortex and parenchymal fibrin deposition in the striatum are significantly higher at $4 \mathrm{hr}$ of MCA occlusion than at $1 \mathrm{hr}$ of ischemia. These data suggest that cerebral microvascular plasma deficit secondary to MCA occlusion is an ongoing process that expands from the subcortex to the cortex over time of ischemia, and intravascular fibrin deposition directly causes this progressive cerebral microcirculatory impairment. Our finding of a progressive microvascular plasma perfusion deficit after ischemia is consistent with previous studies of embolic ischemia in mice and of permanent MCA occlusion in rats (Dawson et al., 


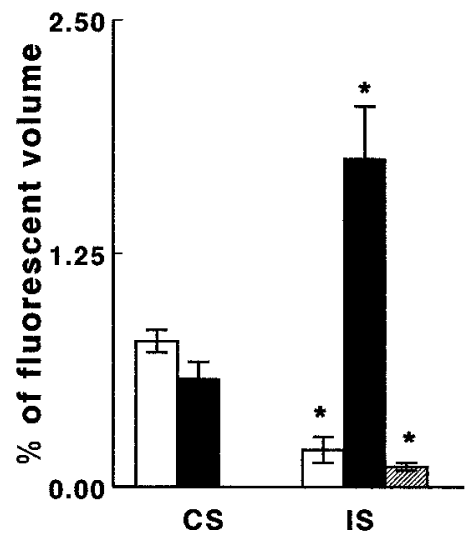

Figure 5. Bar graph shows volumes of perfused cerebral microvascular plasma (open bars), fibrin(ogen) immunoreactivity (hatched bar), and GFAP immunoreactivity ( filled bars) at $1 \mathrm{hr}$ of embolic MCA occlusion. $C S$, Contralateral striatum; IS, ipsilateral striatum.

1997; Zhang et al., 1999a). In addition, our data demonstrate that intravascular fibrin deposition is a primary cause for microvascular plasma perfusion deficit. The potential contribution of fibrin deposition to microcirculatory obstruction was suggested, but not proven, by the observation of fibrin deposition in cerebral microvessels and the parenchyma of the ischemic core in a nonhuman primate model of transient MCA occlusion (Okada et al., 1994). Transcranial Doppler studies reveal a high frequency of asymptomatic microemboli in stroke patients (Siebler et al., 1994). A recent histopathological study confirmed the presence of large numbers of fibrin containing microthromboemboli in the tissue bordering the necrotic brain for stroke patients who died within $7 \mathrm{~d}$ of ictus (Heye and Cervos-Navarro, 1996).

Our data show that microvascular plasma perfusion deficit and intravascular fibrin deposition was primarily colocalized in the subcortex with acute ischemic neuronal damage and activated astrocytes at $1 \mathrm{hr}$ after embolic MCA occlusion. Microvascular plasma perfusion deficit and intravascular fibrin deposition expanded from the subcortex, with severe ischemic cell damage, to the cortex, with less ischemic cell damage, at $4 \mathrm{hr}$ of MCA occlusion, suggesting that acute cerebral microvascular plasma perfusion deficit caused by fibrin deposition may contribute to ischemic cell damage. Our data are in agreement with other experimental findings (Pappata et al., 1993; Heiss et al., 1994; Garcia et al., 1995). CBF values immediately after an MCA occlusion are most reduced in the striatum, and this reduction of CBF expands to the cortex until several hours after MCA occlusion (Pappata et al., 1993; Heiss et al., 1994). There is a significant difference between the percentage of necrotic neurons identified in the striatum (>90\%) compared with the cortex (40\%) at $24 \mathrm{hr}$ after MCA occlusion (Garcia et al., 1995). Moreover, the possibility that early fibrin deposition may contribute to the evolution of the ischemic lesion has clinical implications (Sherman, 1999). When Viprinex, a defibrinogenation compound that primarily reduces plasma fibrinogen levels, was administered to patients within $3 \mathrm{hr}$ after the onset of stroke, patients had improved neurological outcome if their plasma fibrinogen levels were $<70$ $\mathrm{mg} / \mathrm{dl}$ at $9 \mathrm{hr}$ compared with the patients treated with placebo (Sherman, 1999).

Fibrin deposition in the parenchyma of the subcortex with low plasma perfusion and severe ischemic cell damage at $4 \mathrm{hr}$ of embolic MCA occlusion indicates a disruption of blood-brain barrier $(\mathrm{BBB})$ in the ischemic core. A significant increase in fibrin deposition in the ischemic parenchymal tissue has been observed in the ischemic basal ganglia at $24 \mathrm{hr}$ of reperfusion after transient (3 hr) MCA occlusion (Okada et al., 1994). Our data demonstrate that extravascular leakage of fibrinogen molecule takes place without reperfusion after embolic ischemia. Therefore, intravascular fibrin deposition may predispose tissue to increase of BBB permeability, and the subsequent reperfusion accelerates BBB disruption.

The presence of platelets in fibrin suggests that platelet aggregation through interactions between the $\alpha \mathrm{IIb} \beta 3$ integrin on the platelet surface and its primary ligand, fibrinogen, contributes to thromboembolus formation during early stages of embolic ischemia. Consistent with our data are a recent clinical study that demonstrated that administration of Abciximab, a monoclonal antibody, blocks fibrin(ogen) binding to the $\alpha \operatorname{IIb} \beta 3$ integrin to acute ischemic stroke patients, improving neurological outcome compared with placebo (Adams, 1999). In addition, our finding that erythrocytes are enmeshed in fibrin provides an explanation for a previous observation as to why erythrocytes contribute to occlusion of microvascular lumen at $4 \mathrm{hr}$ of MCA occlusion (Garcia et al., 1994).

Activated astrocytes appear to constrict large vessels in the ischemic region after $2 \mathrm{hr}$ of embolic ischemia (Zhang et al., 1999b). In the present study, double immunofluorescent staining
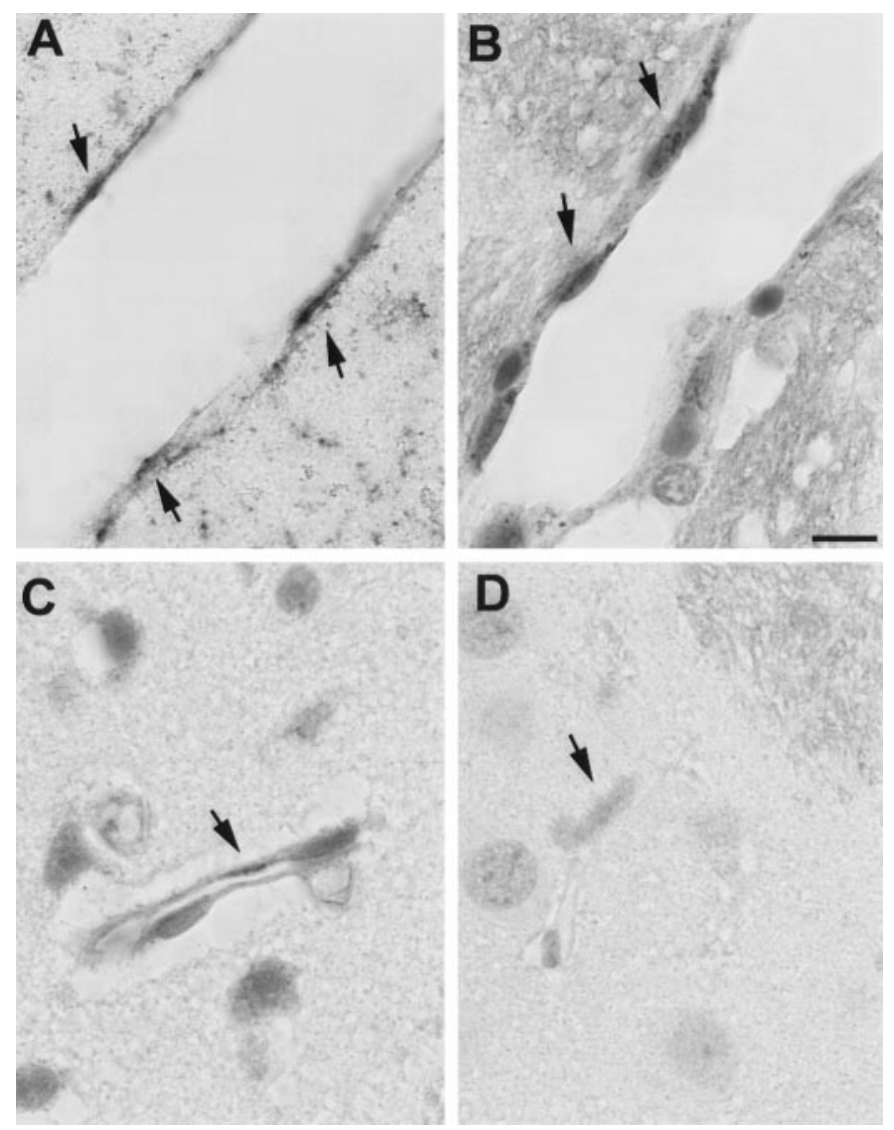

Figure 6. Endothelial cells express PAI-1. PAI-1 mRNA (A, arrows) and PAI-1 antigen $(B, C$, arrows) were present in the cytoplasm of endothelial cells in venules $(A, B)$ and capillaries $(C)$ in the ipsilateral striatum compared with PAI-1-immunonegative vessels in the contralateral hemisphere $(D$, arrow $)$ at $4 \mathrm{hr}$ of embolic MCA occlusion. Immunoreactivity of PAI-1 was visualized by diaminobenzidine. 
for fibrinogen and GFAP revealed that astrocytes are activated at $1 \mathrm{hr}$ of ischemia, as measured by a significant increase of GFAP immunoreactivity. Activated astrocytes surround microvessels that are fibrin-immunoreactive, suggesting that reactive astrocytes may also contribute to cerebral microcirculatory impairments during the early stage of embolic stroke by constricting cerebral vessels.

The specificity of the anti-fibrinogen antibody that we used for fibrin detection is consistent with previous reports on this antibody in a mouse model of thrombosis (Farrehi et al., 1998). In the present study, we found that fibrin(ogen) immunoreactivity was only detected in the ischemic region in both nonperfused and extensively perfused brain tissue but not in tissue from control rats or when the primary antibody was omitted. Furthermore, the fibrin(ogen)-immunoreactive meshwork was found within vessels and extravascular parenchymal tissue in the ischemic region.

PAI-1 is a rapid and specific inhibitor of t-PA and u-PA and is the primary regulator of plasminogen activation in vivo (Loskutoff et al., 1989). However, recent studies demonstrate that neurons in the brain express neuroserpin, which efficiently inhibits activity of t-PA (Osterwalder et al., 1996; Hastings et al., 1997). Elevations in PAI-1 activity have been associated with fibrin deposition after ischemia, and increased plasma PAI-1 levels are correlated with the occurrence of previous ischemic episodes (Hamsten et al., 1987; Margaglione et al., 1994). However, little is known about in situ PAI-1 localization in ischemic brain. Our observations of the induction of PAI-1 mRNA and PAI-1 antigen in the ischemic region after embolic MCA occlusion suggest that local upregulation of PAI-1 may contribute to fibrin deposition during early embolic stroke. In situ hybridization demonstrated induction of PAI-1 mRNA in vascular endothelial cells in the ischemic region at $1 \mathrm{hr}$ of ischemia and a significant increase of PAI-1 mRNA at $4 \mathrm{hr}$ of ischemia.

Immunohistochemical staining showed the same pattern of increased PAI-1 antigen in the endothelial cells. These data indicate that upregulation of PAI-1 is transcriptionally regulated in the ischemic lesion. The endothelial cells synthesize and secrete PAI-1 (Kollros et al., 1994). Platelets are the major reservoir of PAI-1 in blood (Loskutoff et al., 1989; Braaten et al., 1993; Stringer et al., 1994). Inability to detect PAI-1 on platelets in the present study does not rule out the possibility that platelets contribute to increase PAI-1. With fibrin strands of a fresh clot near the endothelial surface, active PAI-1 is bound to the fibrin strands, and is thus protected from fibrinolysis by t-PA (Braaten et al., 1993). In the present study, the time course of upregulation of PAI-1 gene expression in the endothelial cells and presence of platelets are related to the increase of fibrin deposition, suggesting that increases in PAI-1 levels may contribute to stabilization of fibrin deposition within the cerebral microvasculature by a time-dependent increase in fibrinolytic resistance. This view is supported by fibrinolytic therapy with t-PA in this model in which administration of t-PA at $1 \mathrm{hr}$ after MCA occlusion increases $\mathrm{CBF}$ and reduces ischemic lesion volume, but not when t-PA is administered at $4 \mathrm{hr}$ after MCA occlusion (Jiang et al., 1998, 1999). Local increase in PAI-1 expression may be a reason for failure of fibrinolytic therapy at $4 \mathrm{hr}$ of ischemia in this model. Our results are consistent with the recent finding that PAI-1-/mice exhibit less residual thrombus when compared with PAI$1+/+$ mice in a murine arterial thrombotic model (Farrehi et al., 1998).

In summary, intravascular fibrin deposition, composed of erythrocytes, PMN leukocytes, and platelets, directly obstructs cerebral microvascular plasma perfusion. Upregulation of PAI-1 gene in the endothelial cells may foster fibrin deposition through suppression of fibrinolysis. These data suggest that local perturbation of procoagulant and fibrinolytic genes in the brain may be important for cerebral microcirculatory impairment during early focal embolic cerebral ischemia.

\section{REFERENCES}

Adams H (1999) Preliminary safety report of an ongoing dose-escalation trial Abciximab in acute ischemic stroke. Stroke 30:244.

Bereczki D, Wei L, Otsuka T, Acuff V, Pettigrew K, Patlak C, Fenstermacher J (1992) Hypoxia increases velocity of blood flow through parenchymal microvascular systems in rat brain. J Cereb Blood Flow Metab 13:475-486.

Braaten JV, Handt S, Jerome WG, Kirkpatrick J, Lewis JC, Hantgan RR (1993) Regulation of fibrinolysis by platelet-released plasminogen activator inhibitor 1: light scattering and ultrastructural examination of lysis of a model platelet-fibrin thrombus. Blood 81:1290-1299.

Buchweitz-Milton E, Weiss HR (1988) Perfused microvascular morphometry during middle cerebral artery occlusion. Am J Physiol 255:H623-H628.

Collen D, Lijnen HR (1991) Basic and clinical aspects of fibrinolysis and thrombolysis. Blood 78:3114-3124.

Crowell RM, Olsson Y (1972) Impaired microvascular filling after focal cerebral ischemia in the monkey. Modification by treatment. Neurology 22:500-504.

Dawson DA, Hallenbeck JM (1996) Acute focal ischemia-induced alterations in MAP2 immunostaining: description of temporal changes and utilization as a marker for volumetric assessment of acute brain injury. J Cereb Blood Flow Metab 16:170-174.

Dawson DA, Ruetzler CA, Hallenbeck JM (1997) Temporal impairment of microcirculatory perfusion following focal cerebral ischemia in the spontaneously hypertensive rat. Brain Res 749:200-208.

del Zoppo GJ (1994) Microvascular changes during cerebral ischemia and reperfusion. Cerebrovasc Brain Metab Rev 6:47-96.

Ennis SR, Keep RF, Schielke GP, Betz AL (1990) Decrease in perfusion of cerebral capillaries during incomplete ischemia and reperfusion. J Cereb Blood Flow Metab 10:213-220.

Farrehi PM, Ozaki CK, Carmeliet P, Fay WP1 (1998) Regulation of arterial thrombolysis by plasminogen activator inhibitor-1 in mice. Circulation 97:1002-1008.

Garcia JH, Liu KF, Yoshida Y, Chen S, Lian J (1994) Brain microvessels: factors altering their patency after the occlusion of a middle cerebral artery (Wistar rat). Am J Pathol 145:728-740.

Garcia JH, Liu KF, Ho KL (1995) Neuronal necrosis after middle cerebral artery occlusion in Wistar rats progresses at different time intervals in the caudoputamen and the cortex. Stroke 26:636-642.

Hamsten A, de Faire U, Walldius G, Dahlen G, Szamosi A, Landou C, Blomback M, Wiman B (1987) Plasminogen activator inhibitor in plasma: risk factor for recurrent myocardial infarction. Lancet 2:3-9.

Handt S, Jerome WG, Tietze L, Hantgan RR (1996) Plasminogen activator inhibitor-1 secretion of endothelial cells increases fibrinolytic resistance of an in vitro fibrin clot: evidence for a key role of endothelial cells in thrombolytic resistance. Blood 87:4204-4213.

Hastings GA, Coleman TA, Haudenschild CC, Stefansson S, Smith EP, Barthlow R, Cherry S, Sandkvist M, Lawrence DA (1997) Neuroserpin, a brain-associated inhibitor of tissue plasminogen activator is localized primarily in neurons. Implications for the regulation of motor learning and neuronal survival. J Biol Chem 272:33062-33067.

Heiss WD, Graf R, Wienhard K, Lottgen J, Saito R, Fujita T, Rosner G, Wagner R (1994) Dynamic penumbra demonstrated by sequential multitracer PET after middle cerebral artery occlusion in cats. J Cereb Blood Flow Metab 14:892-902.

Heye N, Cervos-Navarro J (1996) Microthromboemboli in acute infarcts: analysis of 40 autopsy cases. Stroke 27:431-444.

Hossmann KA (1990) Hemodynamics of post ischemic reperfusion of the brain. In: Protection of the brain from ischemia (Weistein PR, Faden AL, eds), pp 21-36. Baltimore: William and Wilkins.

Jiang Q, Zhang RL, Z hang Z G, Ewing JR, Divine GW, Chopp M (1998) Diffusion, T2, and perfusion weighted NMR imaging of middle cerebral artery embolic stroke and rt-PA intervention in rat. J Cereb Blood Flow Metab 18:758-767.

Jiang Q, Zhang RL, Zhang ZG, Ewing JR, Jiang P, Divine GW, Knight RA, Chopp M (1999) MRI indices of therapeutic efficacy of rtPA 
treatment of rat at $1 \mathrm{H}$ and $4 \mathrm{H}$ after embolic stroke. J Cereb Blood Flow Metab, in press.

Kitching AR, Holdsworth SR, Ploplis VA, Plow EF, Collen D, Carmeliet P, Tipping PG (1997) Plasminogen and plasminogen activators protect against renal injury in crescentic glomerulonephritis. J Exp Med 185:963-968.

Kollros PR, Konkle BA, Ambarian AP, Henrikson P (1994) Plasminogen activator inhibitor-1 expression by brain microvessel endothelial cells is inhibited by elevated glucose. J Neurochem 63:903-909.

Little JR, Kerr FW, Sundt TM Jr (1975) Microcirculatory obstruction in focal cerebral ischemia. Relationship to neuronal alterations. Mayo Clin Proc 50:264-270.

Loscalzo J, Schafer AI (1992) Anticoagulants, antiplatelet agents, and fibrinolysis. In: Vascular Medicine, a textbook for vascular biology and disease. (Loscalzo J, Creager MA, Dzau VJ, eds), pp 659-682. Boston: Little, Brown.

Loskutoff DJ, Sawdey M, Mimuro J (1989) Type 1 plasminogen activator inhibitor. Prog Hemost Thromb 9:87-115.

Margaglione M, Di Minno G, Grandone E, Vecchione G, Celentano E, Cappucci G, Grilli M, Simone P, Panico S, Mancini M (1994) Abnormally high circulation levels of tissue plasminogen activator and plasminogen activator inhibitor-1 in patients with a history of ischemic stroke. Arterioscler Thromb 14:1741-1745.

Morris DC, Zhang ZG, Davies K, Fenstermacher J, Chopp M (1999) High resolution quantitation of microvascular plasma perfusion in non-ischemic and ischemic rat brain by laser-scanning confocal microscopy. Brain Res Brain Res Protocols 4:185-191.

Okada Y, Copeland BR, Fitridge R, Koziol JA, del Zoppo GJ (1994) Fibrin contributes to microvascular obstructions and parenchymal changes during early focal cerebral ischemia and reperfusion. Stroke 25:1847-1853.

Osterwalder T, Contartese J, Stoeckli ET, Kuhn TB, Sonderegger P (1996) Neuroserpin, an axonally secreted serine protease inhibitor. EMBO J 15:2944-2953.

Pappata S, Fiorelli M, Rommel T, Hartmann A, Dettmers C, Yamaguchi T, Chabriat H, Poline JB, Crouzel C, Di Giamberardino L, Baron JC (1993) PET study of changes in local brain hemodynamics and oxygen metabolism after unilateral middle cerebral artery occlusion in baboons. J Cereb Blood Flow Metab 13:416-424.
Paxinos G, Watson C (1986) The rat brain in stereotaxic coordinates. Ed 2. New York: Academic.

Ploplis VA, Carmeliet P, Vazirzadeh S, Van Vlaenderen I, Moons L, Plow EF, Collen D (1995) Effects of disruption of the plasminogen gene on thrombosis, growth, and health in mice. Circulation 92: 2585-2593.

Plow EF, Herren T, Redlitz A, Miles LA, Hoover Plow JL (1995) The cell biology of the plasminogen system. FASEB J 9:939-945.

Sappino A-P, Madani R, Huarte J, Belin D, Kiss JZ, Wohlwend A, Vassalli J-D (1993) Extracellular proteolysis in the adult murine brain. J Clin Invest 92:679-685.

Sherman DG (1999) Defibrinogenation with Viprinex (Ancord) for treatment of acute ischemic stroke. Stroke 30:234.

Siebler M, Nachtmann A, Sitzer M, Steinmetz H (1994) Anticoagulation monitoring and cerebral microemboli detection. Lancet 344:555.

Soltanian-Zadeh H, Windham JP (1994) Mathematical basis of eigenimage filtering. Magn Reson Med 31:465-467.

Stringer HA, van Swieten P, Heijnen HF, Sixma JJ, Pannekoek H (1994) Plasminogen activator inhibitor-1 released from activated platelets plays a key role in thrombolysis resistance. Studies with thrombi generated in the Chandler loop. Arterioscler Thromb 14:1452-1458.

Vassalii J-D, Sappino A-P, Belin D (1991) The plasminogen activator/ plasmin system. J Clin Invest 88:1067-1072.

Windham JP, Abd-Allah MA, Reimann DA, Froelich JW, Haggar AM (1988) Eigenimage filtering in MR imaging. J Comput Assist Tomogr $12: 1-9$.

Zhang RL, Chopp M, Zhang ZG, Jiang Q (1997) A rat model of focal embolic cerebral ischemia. Brain Res 766:83-92.

Zhang ZG, Davies K, Prostak J, Fenstermacher J, Chopp M (1999a) Quantitation of microvascular plasma reperfusion and neuronal microtubulin-associated protein in ischemic mouse brain by laserscanning confocal microscopy. J Cereb Blood Flow Metab 19:68-78.

Zhang ZG, Bower L, Zhang RL, Chen S, Windham JP, Chopp M (1999b) Three dimensional measurement of cerebral microvascular plasma perfusion, glial fibrillary acidic protein and microtubule associated protein-2 immunoreactivity after embolic stroke in rats: a double fluorescent labeled laser-scanning confocal microscopic study. Brain Res 844:55-66. 